\title{
NOTAS
}

\section{Novedad en la flora pteridofítica de la provincia de Corrientes (Argentina)}

\author{
por GUILLERMINA PELLEGRINI'
}

Summary: Doryopteris triphylla (Lam.) H. Christ is mentioned for the first time for this area. The presence of Doryopteris lorentzii (Hieron.) Diels is confirmed.

El estudio de material de herbario y del coleccionado recientemente en el interior de Corrientes, ha permitido registrar la presencia en esta provincia de 4 especies de Doryopteris.

Doryopteris nobilis (Moore) C. Chr. y D. pedata (L.) Fée var. multipartita (Fée) R. M. Tryon ya habían sido citadas para Corrientes. En el presente trabajo se menciona por primera vez a D. triphylla (Lam.) H. Christ y se confirma la presencia de D. lorentzii (Hieron.) Diels. Se incluye una clave para la determinación de las especies de este género en Corrientes.

\section{Doryopteris triphylla (Lam.) H. Christ}

Bull. Herb. Boissier, sér. 2, 6: 546. 1902.

Sinonimia en Tryon, 1942: 16

Segúu Tryon (1962) y Sehnem (1972), esta especie se encuentra en Paraguay, Uruguay, Argentina y Sur de Brasil. En Argentina se la ha citado para Misiones (Hassler, 1928 y Cartaginese, 1977) y para las sierras de Buenos Aires, Córdoba y el Noroeste argentino (Salta, Tucumán, Catamarca y Jujuy), donde crece en ambientes de chaco serrano y monte pedemontano caducifolio (de la Sota, 1977). En Corrientes ha sido coleccionada recientemente en Garruchos (Dpto. Santo Tomé) en el interior de la selva marginal del río Uruguay, creciendo en los bordes inundables de cursos de agua, sobre suelo rojizo.

\footnotetext{
' Becaria de la SECYT-L . VNE, Corrientes. IBONE, Casilla de Correo 209, 3400 Corrientes, Argentina
}

El siguiente material documenta este hallazgo: ARGENTINA. Corrientes: Dpto. Santo Tomé, Garruchos, 9.II.1993, Tressens \& al. 4396 (CTES).

\section{Doryopteris lorentzii (Hieron.) Diels}

Engler und Prantl, Nat. Pflanzenfam. 1(4):270. 1899.

Sinonimia en Tryon 1942: 34.

En la revisión del género, Tryon (l.c.) establece para esta especie un área que comprende Perú y Bolivia, y el Sur de Brasil hasta Córdoba (Argentina). Entre el material examinado menciona un ejemplar para Corrientes del año 1854, E. Palmer (US), que es señalado en el mapa 5. En trabajos posteriores Tryon (1962) no vuelve a mencionar la especie para Corrientes.

Cartaginese (1977), en su revisión del género para Argentina, no cita material de Corrientes de esta especie, desconociendo la cita de Tryon (1942); al tratar su área de distribución, señala su presencia en el Norte argentino en la selva tucumano-boliviana y en la selva misionera, $\sin$ especificar provincias. Doryopteris lorentzii ha sido mencionada además por Hicken (1908) para las provincias de Tucumán, Chaco y Córdoba; de la Sota $(1972,1977)$ la cita para el Noroeste, donde se halla en el bosque pedemontano, selva basal y bosque montano, Sierras Pampeanas del centro (Córdoba) y para el Noreste (Misiones y Chaco).

El siguiente material confirma la presencia de esta especie: ARGENIINA. Corrientes: Dpto. Capital, Isla Meza, costa oriental, 17.II.1992, Pellegrini 8 (CTES); ídem, 12.XII.1992, Pellegrini 9 (CTES). Dpto. 

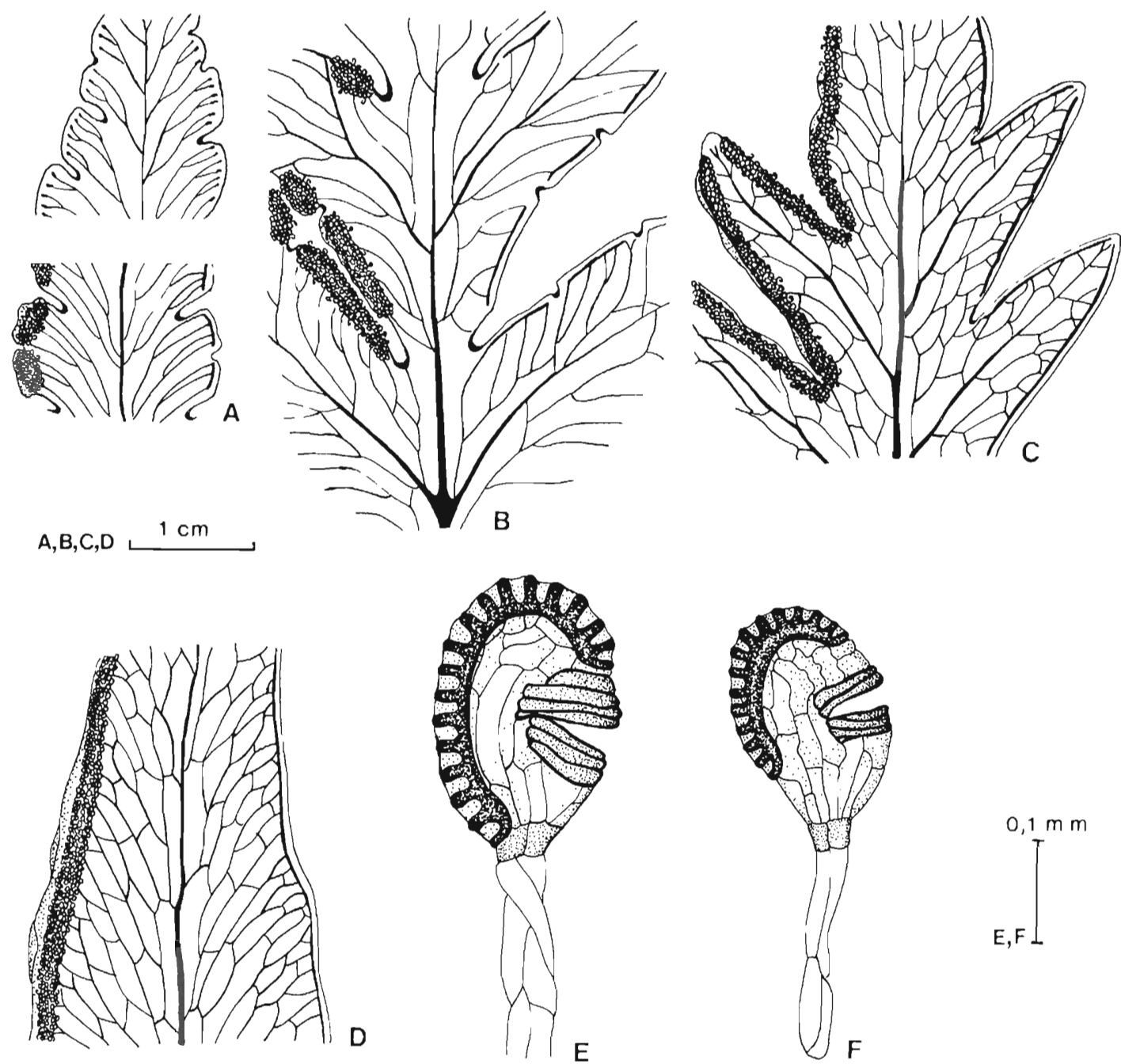

Fig. 1. Doryopteris. A-D, porciones de láminas mostrando la venación, soros y pseudoindusios; en el margen derecho el indusio y los esporangios han sido removidos para mostrar la vena colectora marginal; $A, D$. triphylla, arriba lámina estéril, abajo lámina fértil; $B, D$. lorentzii; $C, D$. pedata var. multipartita; $D, D$. nobilis. E y $\mathrm{F}$, esporangios; $\mathrm{E}, \mathrm{D}$. nobilis; F, D. pedata var. multipartita (A: Tressens \& al. 4396; B: Pellegrini 8; C y F: Tressens \& al. 4455, CTES; D y E: Heinonen \& al. 1, CTES).

Empedrado, río Empedrado y Ruta 12, 31.VIII.1973, Quarín \& Schinini 1210 (CTES); $2 \mathrm{Km} S$ de Derqui, 2.VII.1974, Schinini \& González 9408 (CTES).

Obs. En la revisión del género realizada por Cartaginese (1977), así como en otros trabajos para la flora de Argentina (de la Sota, 1972 y 1977) se considera a Doryopteris concolor (Langsd. \& Fisch.) Kuhn como una de las especies que viven en el nuestro país. En este trabajo no se incluye esta especie, siguiendo el criterio de Tryon (1981), quien la transfirió a
Cheilanthes Sw. Tryon \& Tryon (1982) afirman que con esta transferencia el género Doryopteris es más homogéneo y que Cheilanthes en cambio, como consecuencia de las numerosas adiciones, se ha constituido en un grupo amplio y heterogéneo. Estos autores proponen un trabajo sistemático que abarque a los grupos emparentados, permitiendo así el esclarecimiento y segregación de los géneros.

Hasta tanto estos estudios se realicen, se sigue el criterio de Tryon y no se considera aquí a D. concolor. 
La siguiente clave permite la identificación de las especies de Doryopteris en Corrientes. En la Figura 1 se ilustran los caracteres de valor diagnóstico.

1. Vemación libre.

1. D. triphylla

1'. Venación parcial o totalmente areolada.

2. Venación parcialmente areolada. Aréolas a lo largo de las venas mayores en una sola serie, venas marginales libres.

2'. Venación totalmente areolada.

2. D. lorentzii

3. Yemas vegetativas en la base de la lámina. Anillo del esporangio con 17 células, partiendo desde la base misma del cuerpo de] esporangio.

3. D. nobilis

3. Yemas vegetativas ausentes en la base de la lámina. Anillo con 14 células, partiendo no desde la base del cuerpo del esporangio, sino algo por encima de la misma.

4. D. pedata var. multipartita

\section{Agradecimientos}

Deseo expresar mi agradecimiento a Sara G. Tressens por la orientación y estímulo brindado durante la realización de este trabajo.

\section{Bibliografía}

CARTAGINESE, M.S. 1977. Revision del género Doryopteris en Argentina. Revista Mus. Argent. Ci. Nat. Bernardino Rivadavia Inst. Nac. Invest. Ci. Nat., Bot. 5, 5:105-122, 8 lám.

HASSLER, E. 1928. Pteridophytorum Paraguariensium et reginum argentinarum adjacentium conspectus criticus. Enumeración de las Pteridofitas del Paraguay, Misiones argentinas y Gran Chaco conocidas hasta el año 1921. Trab. Inst. Bot. Farmacol. 45:1-102.

HICKEN, C. M. 1908. Polypodiacearum Argentinarum. Catálogo de las Polipodiáceas Argentinas. Revista Mus. La Plata, Secc. Bot. 15, 2a. s. 2:226-282.

SEHNEM, A. 1972. Pteridáceas, en Reitz, (ed.) Fl. Ilustr. Catarinense [PTER]:1-244, 61 est., 45 mapas.

SOTA, E. R. de la. 1972. Sinopsis de las Pteridofitas del Noroeste de Argentina, I. Darwiniana 17:11-103, 3 láms., 5 figs.

-1977. Pteridofitas, en A. L. Cabrera, Flora de la Provincia de Jujuy. Col. Ci. INTA 13(2):XIV + 275 págs. 108 figs.

TRYON, R. M. 1942. A revision of the Genus Doryopteris. Contr. Gray Herb. 143:1-80, 8 láms., 12 mapas.

-1944. Dynamic phytogeography of Doryopteris. Amer. J. Bot. 31:470-473, 17 mapas.

- 1962. The Fern genus Doryopteris in Santa Catarina and Rio Grande do Sul, Brazil. Sellowia 1.4:51-59.

TRYON, R. M. \& A. F. TRYON. 1981. Taxonomic and nomenclatural notes on ferns. Rhodora 83:133. 1982. Ferns and Allied Plants. With Special Reference to Tropical America. Springer-Verlag, Berlin, Heildeberg, New York, 857 págs., 2028 figs. 